\title{
The Effects of Cooperative Learning in Enhancing the Performance Level of Grade-10 Mathematics Students in Talavera National High School in the Philippines
}

\author{
Analyn D. Gamit ${ }^{1}$, Jacquiline A. Antolin ${ }^{2}$, Arneil G. Gabriel ${ }^{3}$ \\ ${ }^{1}$ Department of Quality Assurance and Accreditation, Nueva Ecija University of Science and Technology, Cabanatuan City, \\ Philippines \\ ${ }^{2}$ Department of Education, Talavera National High School, Talavera, Philippines \\ ${ }^{3}$ Department of Public Administration, Nueva Ecija University of Science and Technology, Cabanatuan City, \\ Philippines \\ Email: opats14@yahoo.com
}

How to cite this paper: Gamit, A.D., Antolin, J.A. and Gabriel, A.G. (2017) The Effects of Cooperative Learning in Enhancing the Performance Level of Grade-10 Mathematics Students in Talavera National High School in the Philippines. Journal of Applied Mathematics and Physics, 5, 2386-2401. https://doi.org/10.4236/jamp.2017.512195

Received: November 22, 2017 Accepted: December 26, 2017 Published: December 29, 2017

Copyright $\odot 2017$ by authors and Scientific Research Publishing Inc. This work is licensed under the Creative Commons Attribution International License (CC BY 4.0).

http://creativecommons.org/licenses/by/4.0/

\begin{abstract}
Mathematics is considered by many students as a difficult academic subject. To improve their performance, various learning strategies are employed by teachers abandoning the conventional method. This study focused on the cooperative learning as a method to enhance level of performance of grade 10 mathematics students in the Philippines. It looked into the method and how it influenced students' performance. By using a quasi-experimental research method, the following results are generated: 1) the method positively improved the performance in mathematics of the control and experimental groups; 2) while effectiveness assessment showed a highly effective result; and 3) the application of the method showed a positive impact on the participants as shown by their positive perception of the subject mathematics.
\end{abstract}

\section{Keywords}

Mathematics, Cooperative Learning, Academic Performance, Grade 10 Component

\section{Introduction}

Mathematics is considered the mother of all learnings in both Arts and Sciences. It is a tool for understanding structures, relationships and patterns to produce solutions for complex real life problems. But many students possessed of nega- 
tive perception on mathematics as an academic discipline. This feeling effectively hindered their potential to learn and understand mathematical problem. Consequently, for them to cope with the negative perception, modern day teachers and scholars employed innovations in teaching mathematics to help students overcome fears and improve their performance on the subject. While providing appropriate method to study mathematics is found to be relative, debates on the issue remain the subject of many scholarly studies. It is believed that cooperative learning can considerably improve students' level of performance in the subject compared to the conventional/traditional method of teaching [1]. Cooperative learning is defined and conceptualized by many related literature as a teaching method whereby students support each other by working in a team. Each student contributes their own effort to promote the group performance. Learners elaborate concepts that promote deep understanding while teachers act as facilitators by providing instructional materials. In cooperative learning, they are actively involved in the process of learning and understanding very much different from conventional learning where teacher is viewed at the core of the learning process. The method of cooperative learning is deemed better because it takes place through socialization by working together and achieving common learning goal while developing the students well rounded personality and longer learning retention [2]-[11].

Alongside the advantages of cooperative learning, many educators still resort to conventional learning to teach mathematics to secondary students. The conventional method of teaching math is still regarded as proven and tested for the students to absorb learning. In the middle of debates, this study is done to affirm the importance of cooperative learning as a better teaching strategy in mathematics compared to conventional method. The present paper is also written to validate some claims on the effectiveness of cooperative learning to [12] grade 10 students in the Philippines.

\section{Statement of the Problem}

This study aimed to investigate the effects of cooperative learning strategy in enhancing the performance level of grade-10 students in Algebra at Talavera National High School, Philippines.

Specifically, the study sought to:

1) Describe the performance level of the students on the control and experimental group before and after the experiment.

2) Assess the effectiveness of cooperative learning.

3) Determine the impact of cooperative learning on students' performance in Mathematics.

The study is divided into four parts. The first part contains the introduction and the related literature. The second part deals with the methodology employed in the study. The third part contains the results of the quasi experiments and the discussion. Among the highlights of the discussion are: the Pre-Test of Control 
Group and experimental group to measure the level of performance of grade 10 students in Mathematics using cooperative learning. Both the pre test and post tests are measured. It is followed by the measurement of impact of cooperative learning and the summary, conclusion and recommendations.

\section{Methodology}

\subsection{Conceptual Framework of the Study}

Lev Vygotsky (1896-1934), believes that learning and development is a collaborative activity and that children are cognitively developed in the context of socialization and education [11]. This socialization in education is generally termed as cooperative learning. This method is best understood in terms of how individuals use information, resources and help others to build and improve their mental models and their problem solving strategies. It is a method reinforce by instructional scaffolding which is also known to be one of the popular constructivist's pedagogies. It is a technique whereby the teacher stimulates the desired learning strategy or task, and afterwards the learners take full responsibility to their own work. From the existing body of knowledge the paper's research paradigm is made and shown in Figure 1, and used to illustrate the relationships of each component of instructional process with the students' academic performance.

The Figure 1 shows the overview of the study. The study is composed of three phases: The pre assessment phase, cooperative learning phase and the post assessment phase. The researcher administered a pre-test to both groups to describe the level of academic performance of each student in Mathematics 10. The result of this served as the independent variable for comparing the results of the assessment after the intervention has been done. It served as the baseline of how

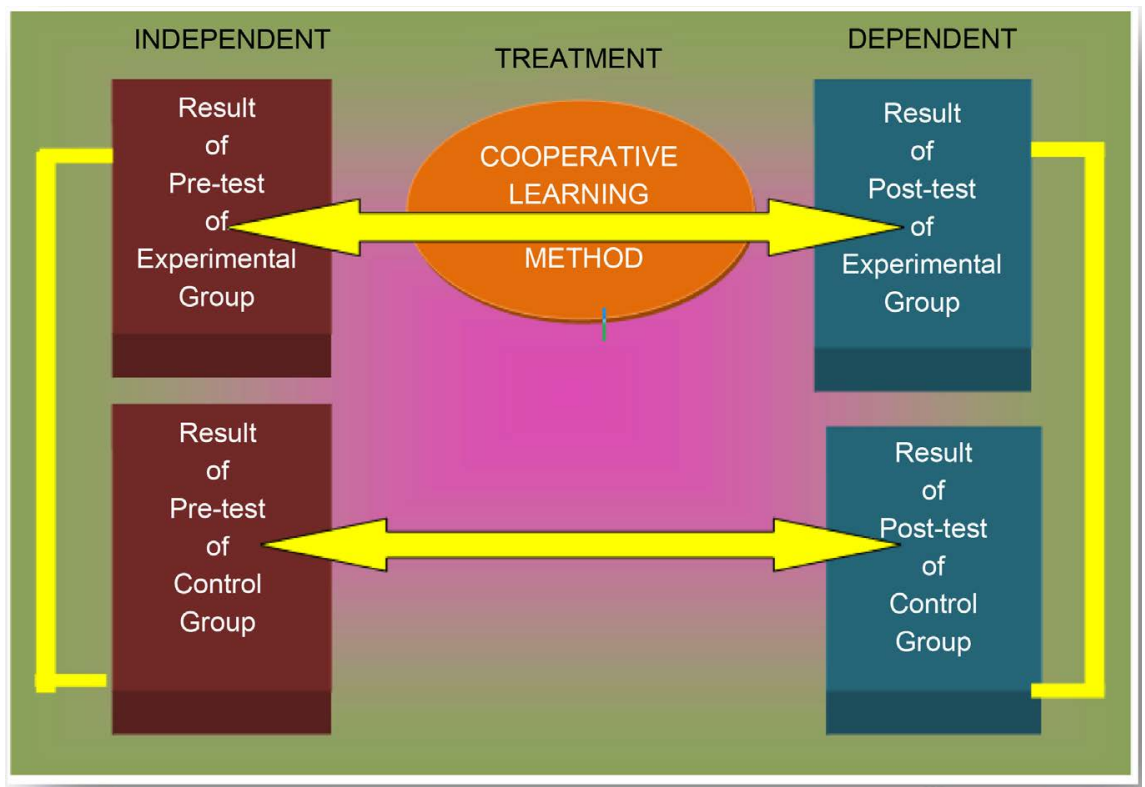

Figure 1. Research paradigm. 
the respondents improved after the intervention (Cooperative Learning Method) which served as the treatment period where the students under the experimental group worked as a team in which they have an equal opportunity to share and contribute their ideas regarding their group task. The high performing students served as mentors or coach to their peers for better understanding of the lessons being discussed. During the cooperative learning process, the researcher provided learning materials as supplemental tools to students' learning. These materials are teacher-made learning materials, or activities to accomplish or perform by the students during cooperative learning sessions. The researcher also used other sources such as internet and mathematics books to supplement the teaching-learning materials. Finally the Post-assessment phase was undertaken to determine the progress of their learning in mathematics. During this stage, the students were assessed using test material similar with the pre test. Some modifications have been made to ensure the reliability of the result. This phase determined if the cooperative learning method helped improve the academic performance of students under experimental group in Mathematics.

\subsection{Research Locale}

This study was conducted at Talavera National High School (TNHS), in Talavera, Nueva Ecija during the school year 2016-2017. TNHS is located at Roxas Street, Pag-asa District, Talavera, Nueva Ecija near the municipal hall of Talavera. Figure 2 shows the research locale.

Talavera National High School (TNHS) is one of the largest schools in Nueva Ecija having the total population of almost 5000 as of school year 2016-2017. TNHS offered different curriculum: Basic Education Curriculum (BEC), Special Program in Sports (SPS), Information Technology and Communication (ICT), and Science and Technology Engineering Mathematics (STEM).

\subsection{Research Design}

The method used in this research is the quasi-experimental. It involves the

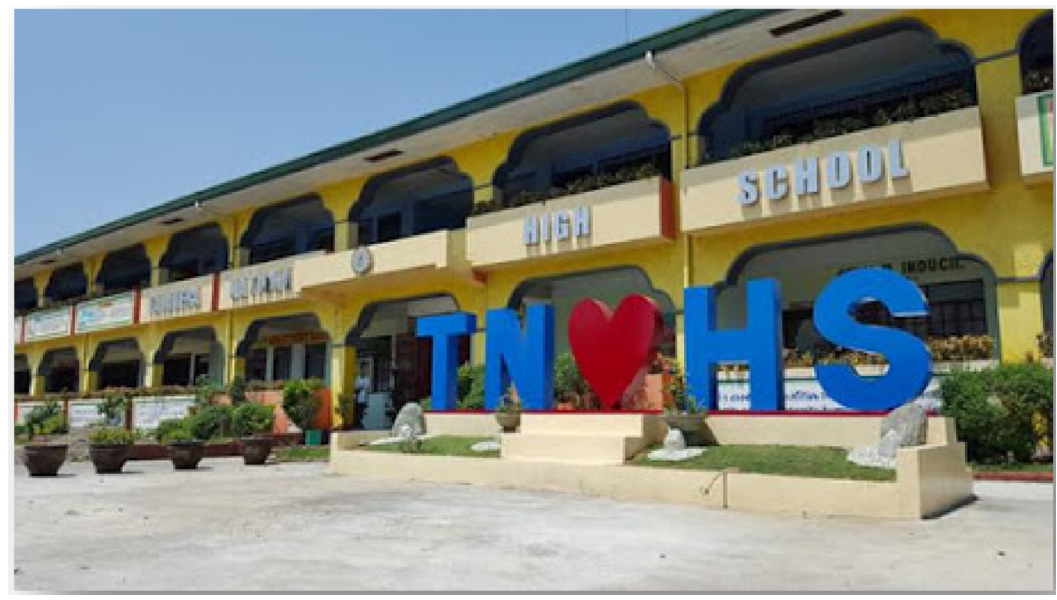

Figure 2. Locale of the study. 
creation of comparison groups-the experimental group and the control group. The experimental group is the subject that is manipulated or exposed to instructional intervention after which an intended outcome is observed and the control group was used as a baseline measure in which it is similar on experimental group in terms of their grade level and mental ability such that it does not receive the treatment or the experimental manipulation that the treatment group receives.

In this design, one group is given the treatments and the other receives no treatment over the same period of time but undergoes exactly the same tests.

\subsubsection{The Respondents}

Purposive sampling was used in the study where it is a form of sampling which determines similar traits or specific characteristics of the participants. The study involved two sections of Grade 10 students who enrolled in Basic Education Curriculum (BEC) and taught by the same teacher in morning session. This two (2) combined classes of Grade 10 students at Talavera National High School for the School year 2016-2017 were chosen in this study in which those respondents belong to heterogeneous group of classes.

\subsubsection{Instruments}

The study made use of different instruments described as follows:

Pre-Test.

A teacher-made test consisting of 40 items which was administered to both treatment and control groups in order to determine the students' level of performance before the conduct of the study. The test was a multiple choice type of test in which each correct answer received one point. The instrument was tried-out to other classes in which the results were analyzed. Hence, "good" and "very good" items were retained, "moderately good" items were revised and "poor" items were discarded and replaced.

\subsubsection{Procedure of the Study}

The procedure of the study involved three phases: pre-assessment phase, the experiment phase, and the post-assessment phase. The procedure is shown on Figure 3.

The Pre-Assessment Phase consists of a given pre test on the Polynomial topics of Mathematics 10 in order to assess their level of academic performance before the conduct of the study.

The Experimental Phase is characterized by the researcher using cooperative learning method to treat the group while the control group was taught using the traditional method of teaching -lectures and discussion method. The focus was

$$
\begin{array}{llccc}
\text { Experimental Group } O^{1} & \text { Treatment } & 0^{3} \\
\text { Control Group } & O^{2} & \mathrm{X} & \mathrm{O}^{4} \\
& \text { Pre - Test } & & \text { Post - Test }
\end{array}
$$

Figure 3. Pre-test and post-test design. 
on individual learning. The control group is the one that is not engage in cooperative learning. The control group is treated using traditional lecture method with individual assignments. The research was conducted on August 1, 2016 to August 29, 2016.

\subsubsection{Statistical Data}

To describe the students' performance level before and after the experiment of cooperative learning, the frequency count and the level of proficiency assessment tools (DepEd Order No. 73, S 2012) as presented in Table 1 were used. Furthermore, pie charts were utilized to present the data. The performance level assessment used is the standard based assessment under DepEd Order No. 73 S. 2012 implemented nationwide on the elementary and secondary basic education curriculum on private and public school. The performance of the students was described in terms of the following:

1) To assess the effectiveness of cooperative learning method on the performance level of students in Mathematics, the t-test for independent variable was used for the comparison of post-test of two samples.

2) To determine the impact of cooperative learning method on the students' performance the t-test for dependent variable was applied on experimental group.

\section{Results and Discussion}

The students' level of performance in Mathematics was described in terms of the result of their pre test and post test through proficiency level prescribed by DepEd.

\subsection{Students' Performance Level}

\subsubsection{Pre-Test of Control Group}

As shown in Figure 4, the students' performance level in Mathematics during their pre-examination of control group is distributed as follows: only 2 out of 41 students or $5 \%$ had a developing proficiency level; and 39 out of 41 students or $95 \%$ had a beginning proficiency level and no one achieved the advance level of performance. It shows that most of them got very low scores during their pre-test. This concludes that most of them have poor performance level in Mathematics during pre-examination.

Table 1. Performance level assessment tools.

\begin{tabular}{cc}
\hline Level of Proficiency & Equivalent Numerical Value \\
\hline Beginning (B) & $74 \%$ below \\
Developing (D) & $75 \%-79 \%$ \\
Approaching Proficiency (AP) & $80 \%-84 \%$ \\
Proficient (P) & $85 \%-89 \%$ \\
Advanced (A) & $90 \%$ above
\end{tabular}




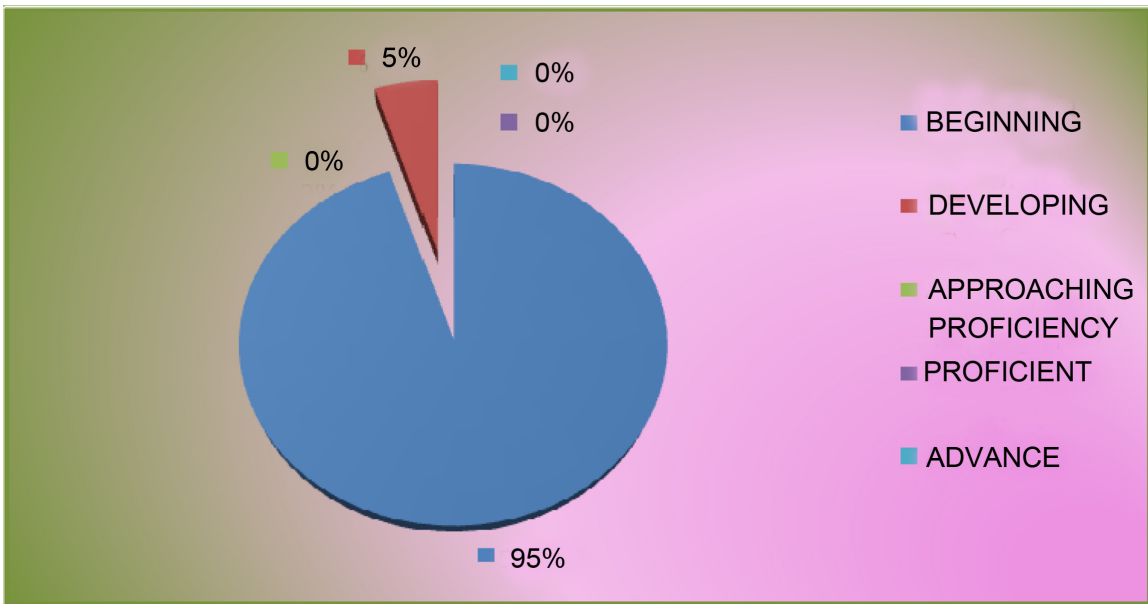

Figure 4. Students' performance level on pre-examination (control group).

\subsubsection{Experimental Group}

As gleaned out in Figure 5, the students' performance level in Mathematics under experimental group during their pre-test examination is distributed as follows: only 1 out of 41 or $2 \%$ had a developing proficiency level; and 40 out of 41 students or $98 \%$ of the total population had a beginning proficiency level and no one of this group reached the advance level and even the proficiency level of performance. The result of the test clearly revealed that the majority of the respondents of both groups have not arrived at the expected competency in their subject. The result of pre-test was needed to determine the level of their competency before the intervention.

\subsection{Students' Performance Level on Post Examination}

Since the objective of this research study is to determine the effects of the cooperative learning method in teaching Mathematics, a post-test was administered to student respondents after the intervention has been done. Thus, the results are presented as follows.

\subsubsection{Control Group}

As shown in Figure 6, the students' performance level in Mathematics as a result of their post examination is distributed as follows: $11 \%$ or $27 \%$ had a beginning proficiency level; $25 \%$ or $61 \%$ had a developing proficiency level; and $5 \%$ or $12 \%$ had an approaching proficiency level. The given data above figure out that most of the respondents under control group attained the developing proficiency level of performance.

It is clearly stated that although there is an intervention implemented in this group, the result shows that there is a big percentage on the population belonging to beginning proficiency level. This also implies that even though teaching and learning process occurred, the result shows that most of them reached only the developing proficiency stage in which it visualized lacking of skills. It is also revealed that no one of them attained the proficient and advance level in the 


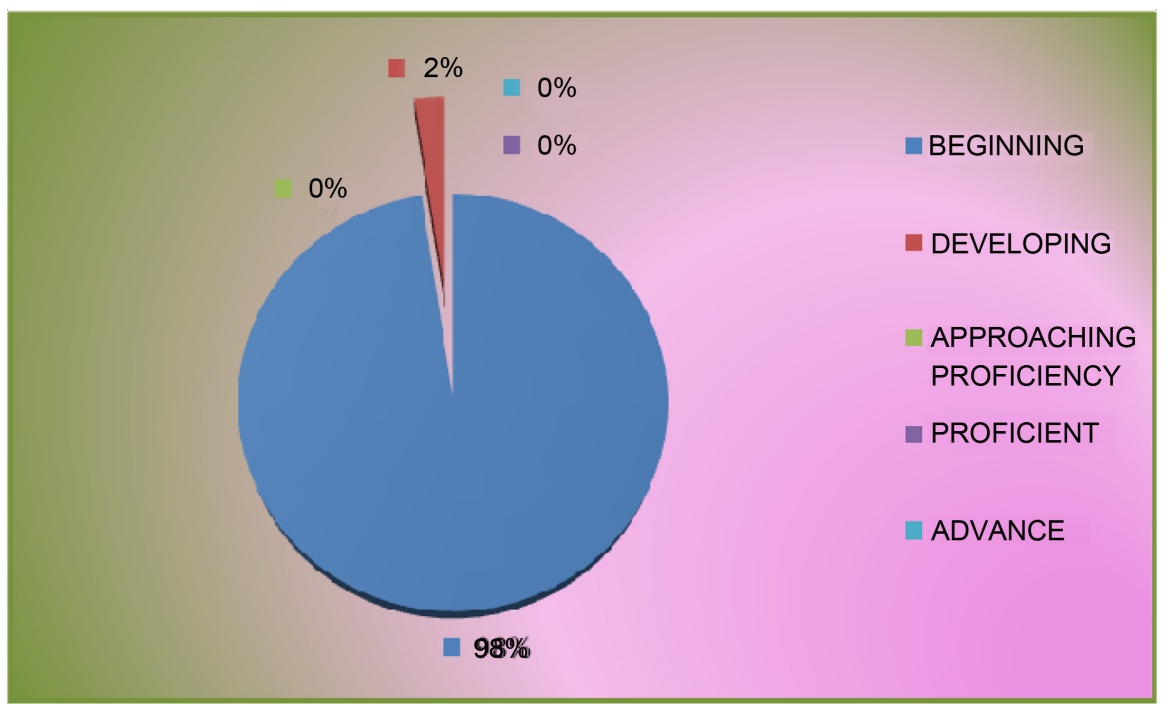

Figure 5. Students' performance level on pre-examination (experimental group).

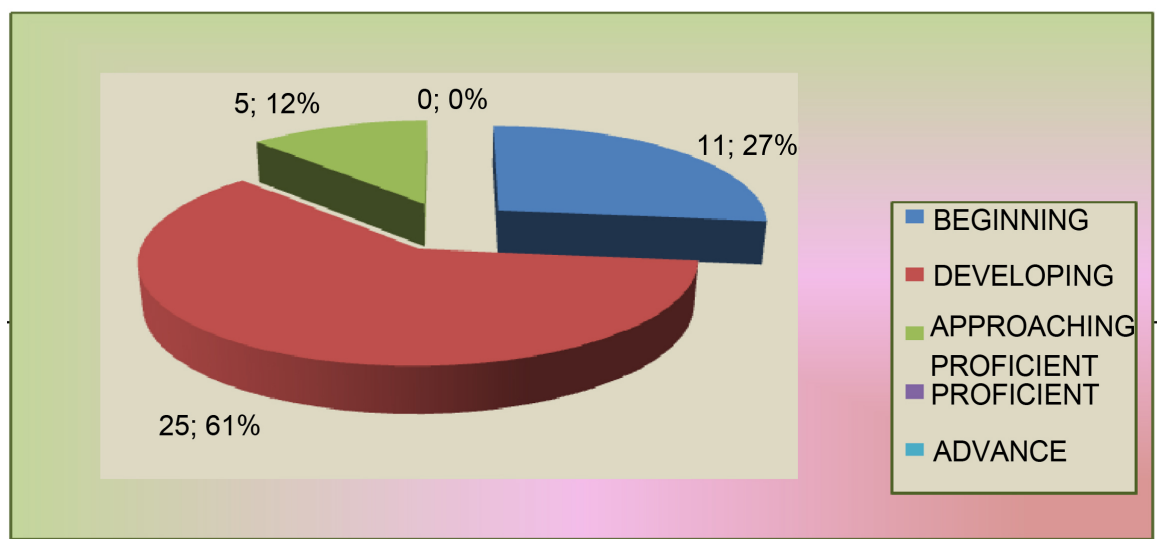

Figure 6. Students' performance level on post examination (control group).

performance level on their post examination.

Some of the respondents under control group divulged that they experienced difficulty on different topics in their lessons, that they needed enough time to make it clearly analyzed because they told that even the basic mathematics skills are complicated for them.

The result of post-test revealed that control group experienced difficulty on performing division of polynomials using long method because of deficiency of skills in addition and subtraction of polynomials.

On the other hand, finding the roots of polynomial equation using the Rational Root Theorem and problem solving involving polynomial equation were the topics that the control group found it problematical.

\subsubsection{Experimental Group}

As illustrated in Figure 7, the students' performance level in Mathematics during their post examination is distributed as follows: $1 \%$ or $2.44 \%$ had a beginning proficiency level; $11 \%$ or $26.83 \%$ had a developing proficiency level; and $28 \%$ or 


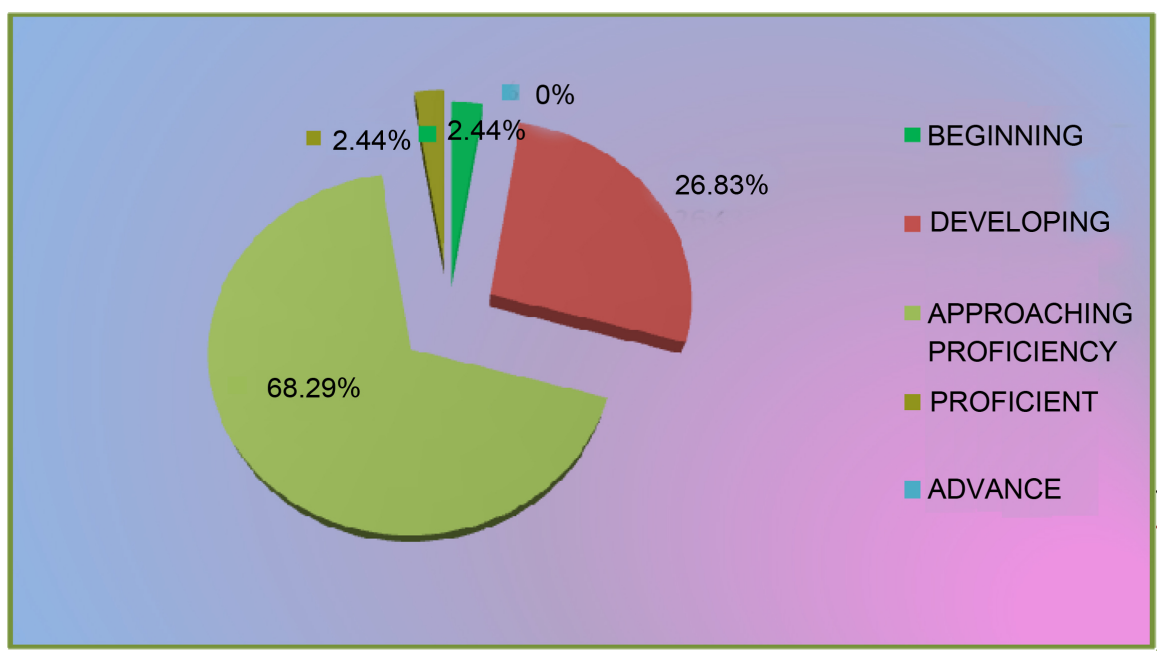

Figure 7. Students' performance level on post examination (experimental group).

$68.29 \%$ had an approaching proficient level; $1 \%$ or $2.44 \%$ had a proficient performance level. Most of them had an approaching proficiency level in Mathematics during post examination.

It is gleaned in the figure that only a very small percentage was in the beginning group. Since, individual difference come to mind in every situation, and the development of every learners differ from each other, a little part of the respondents in experimental group did not reach the expected proficiency level.

On the other hand, the positive result is, some of the students have reached the proficiency level and majority are in the approaching proficiency level as compared to the control group in which majority of them are still in the developing level and no one reached the proficient level.

\subsection{Assessment of the Effectiveness of Cooperative Learning}

The results of the given table below assess the effectiveness of the implemented teaching strategy.

Above Table 2 shows the result of pre-test of experimental and control groups. During pre test of the group, the computed t-value is 1.33 while the critical value is 1.99 at the 0.05 level of significance. The t-value is less than the critical value that signifies that there is no significant difference between the means pre-test performance of the two groups of students before the intervention. It means that two groups are comparable that they are similar in level when referring to the learning competency that they learned during the previous year of their study. This also implies that they had the same level of performance before the treatment.

The result of pre-test of both groups in their scores conveys that they need more attention in terms of their academic performance and innovative instruction because the result of data served as a basis to determine that they belong to the low performing students.

The Table 3 below shows the results of post test of both groups wherein the 
Table 2. Result of compared pre-test of experimental and control group using t-test for independent sample.

\begin{tabular}{cccc}
\hline Test & t-value & t-critical & Interpretation \\
\hline Pre-test & 1.33 & 1.99 & Not significant \\
\hline
\end{tabular}

Table 3. Result of compared post-test of experimental and control group using t-test of independent sample.

\begin{tabular}{cccc}
\hline Test & t-value & t-critical & Interpretation \\
\hline Pre-test & 6.60 & 1.99 & Significant \\
\hline
\end{tabular}

computed t-value is 6.60 and the $t$-critical value is 1.99 . Since the $t$-value is greater than the critical value, it implies that there is a statistical significant difference between the means post test performance of the two groups of students after intervention.

It reveals that after the period of intervention, the performance of experimental group was further improved than the control group. Although there is also an instructional treatment on control group, it is noticeable that there is a big impact on the performance of experimental group after the post-test.

To further emphasize the result of the given data, the researcher made an interview to some of the respondents on both groups.

Some of the respondents under control group opened that they need an extra time to practice more to gain mastery skills on every topics in Mathematics. They lose their eagerness on solving problems because of difficulties in performing operations on polynomials, factoring polynomials, finding the roots of polynomial equations and solving problems involving polynomial equations.

On the other hand, lacking of difficulties on basic Mathematics skills will be resolved by means of peer tutoring and group studying. Some of the respondents on the experimental group revealed that they enjoyed group studying especially when there is a weekly quiz. According to them, two heads are better than one, because with the help and support of everybody, they could bring the level of their performance to the highest level.

This data clearly points out that computed t-value of the difference of score of pre-test and post-test of two groups is 5.11 which are greater than the value of $\mathrm{t}$-critical which is 1.99 .

Even if both groups received different instructional treatment, it shows that there is a statistical significant difference between the scores in pre-test and post test of the respondents in which it manifested that there is a big improvement in terms of academic performance in Mathematics of experimental group.

The given result in Table 4 shows that experimental group excels enough than control group. After two months of intervention period, the experimental group improved the basic skills in Mathematics little by little. They showed lot of patience and eagerness on their individual activity after group task activity. 
Table 4. Result for score difference of pre-test and post-test of respondents using t-test.

\begin{tabular}{cccc}
\hline Test & t-value & t-critical & Interpretation \\
\hline Pre-test & 5.11 & 1.99 & Significant \\
\hline
\end{tabular}

The willingness of experimental group in doing their task with their teammates clearly visualized that the effectiveness of cooperative learning method on experimental group is observable that the intervention improved their academic performance level in Mathematics.

\subsection{Determine the Impact of Cooperative Learning Method on the Students' Performance in Mathematics}

The given table presents how cooperative learning gave a positive impact on the performance of experimental group during intervention.

Based on the study of the result shows those students' negative attitudes toward mathematics in which this perception clearly affects the performance of the students.

Table 5 summarized the result of pre-test and post-test of control group. The computed t-value of control group is 14.40. Since the $t$-value is greater than the critical value; it implies that there is a statistical significant difference between the means pre-test and post test performance of control group of students after intervention. It implies that there is a progress of the performance of this group after the given intervention. It affects the performance of group in which there was an instructional treatment during the period of the study.

The result of pre-test and post-test of experimental group presented on Table 6 above summarized that the computed t-value which is 16.10 is greater than the critical value which is 2.02 wherein it signifies that there is a significant difference between the performance of experimental group before and after the intervention.

The results show that the performance of the students have a better improvement using cooperative learning method as teachers' instructional strategy in teaching Mathematics.

Positively, through comparison of pre-test and post-test and the corresponding proficiency level of experimental group, it is proven that cooperative learning method gave a big impact on the part of the respondents.

The result of post-test of experimental group reveals that even though there is a difficulty on basic Mathematics skills of the respondents in addition and subtraction of polynomials which is the part of division of polynomials, through group studying aided with scaffolding learning materials, it unlocks those difficulties that makes them easy on how to divide polynomials using long method of division.

It is important that before introducing new Mathematical skills, reviewing of previous skills through drill activities will lead to a successful teaching and learning process. 
Table 5. Results for the pre-test and post-test of control group using t-test.

\begin{tabular}{cccc}
\hline Respondent & t-computed & t-critical & Interpretation \\
\hline Control & 14.40 & 2.02 & Significant \\
\hline
\end{tabular}

Table 6. Results for the pre-test and post-test of experimental group using t-test.

\begin{tabular}{cccc}
\hline Respondent & t-computed & t-critical & Interpretation \\
\hline Experimental & 16.10 & 2.02 & Significant \\
\hline
\end{tabular}

Furthermore, the experimental group shows their enthusiasm in every group activities especially when there is a group game like Math relay. Through these activities, teaching mathematics in this way boosts the confidence of every respondent and makes the lesson more active than using traditional way of teaching.

Additionally, it is clearly manifested that learners are more comfortable in doing tasks with their peers to lessen their stressful feelings on solving different problems and activities in Mathematics.

Based on the researcher's observation group work activities are highly effective in discovering the concepts of polynomials, as well as determining the number of terms, the leading coefficient and the constant terms in polynomial through group conversation.

Using scaffolding learning materials, the learners practice their Mathematics skills effectively that are pre-requisite on division of polynomials.

Dealing with problems involving polynomials is not that easy for every student wherein most of them felt uncomfortable when the teachers introduce this topic. Using questionnaire cards, the experimental group showed their passion dealing with factoring polynomials with their teammates.

Meanwhile, even though group companion in finding the roots of polynomial equations using The Rational Root Theorem did not find it very effective. Evidently, it is more effective than doing this task alone.

On the other hand, group games made the discussion more active where the learners appreciated their lessons and enjoyed while learning. Although it is time consuming and needs much effort in executing this group game, it is very appreciative on the part of the teacher.

Peer mentoring is also one of the remarkable strategies on cooperative learning method wherein the results find it effectively. In this method, students are responsible for their performance in which they helped each other to achieve the expected performance level in every task. Learning Together by means of sharing ideas led to a better output and assured the long term mastery skills.

Lastly, problem solving activities through visual presentation, and scaffolding materials made the discussion more effective than using a spoon feeding teaching strategy. The learners constructed freely different solutions on how to solve it properly.

Generally, it clearly exhibited a positive effect towards cooperative learning 
method on the performance of students, as well as positive attitudes towards learning.

This study aimed at determining the effectiveness of cooperative learning method on academic performance level of two groups of grade 10 students in Mathematics at Talavera National High School during school year 2016-2017. The study used pre-test and post test which were administered to conclude if there is a significant difference between the performance of control group and experimental group as a result of the conduct of this study.

\section{Summary, Conclusion and Recommendation}

\subsection{Students' Performance Level}

The performance level of the students was described in terms of the result of their pre test and post test.

\subsubsection{Result of Pre-Test (Control Group)}

The students' performance level in Mathematics during their pre-examination is distributed as follows: only $2 \%$ or $5 \%$ had a developing proficiency level; and 39 of the students or $95 \%$ had a beginning proficiency level.

\subsubsection{Result of Pre-Test (Experimental Group)}

The students' performance level in Mathematics during their pre-test is distributed as follows: only $1 \%$ or $2 \%$ had a developing proficiency level; and 42 of the students or $98 \%$ had a beginning proficiency level.

\subsubsection{Result of Post Test (Control Group)}

The students' performance level in Mathematics during their post examination is distributed as follows: $11 \%$ or $27 \%$ had a beginning proficiency level; 25 or $61 \%$ had a developing proficiency level; and $5 \%$ or $12 \%$ had an approaching proficiency level. Most of them attained a developing proficiency level after receiving instruction using a lecture/discussion method.

\subsubsection{Result of Post Test (Experimental Group)}

The students' performance level in Mathematics during their post examination is distributed as follows: $2 \%$ or $5 \%$ had a beginning proficiency level; $12 \%$ or $28 \%$ had a developing proficiency level; and $28 \%$ or $65 \%$ had an approaching proficiency level; or $1 \%$ or $2 \%$ had a proficient performance level. In line with this, most of them achieved an approaching proficiency level in Mathematics after receiving instruction using a cooperative learning method.

At $5 \%$ level of significance, the $t$-value for the post-test of two groups is 7.85 which is much greater than the 2.03 critical values. The result showed that there is really a significant difference between the performance of the control group and experimental group.

The mean averages of the control and experimental groups are 16.58 and 21.94 respectively, which revealed that the experimental group using the cooper- 
ative learning method performed better than the control group using the traditional lecture/discussion method.

\subsection{Effectiveness of Cooperative Learning}

Based on the result using a given questionnaire to determine the effectiveness of cooperative learning activities the average mean is 4.20 , where the verbal interpretation is moderately effective. The students' perception toward the effectiveness of cooperative learning method revealed that it is highly effective.

\subsection{The Impact of Cooperative Learning Method on the Students' Perception in Mathematics}

Based on the result using a questionnaire, the average computed mean is 4.10 where the verbal interpretation is moderately agree, the students' perception with regards to cooperative learning method exhibits a positive effect towards cooperative learning method on academic performance of students, as well as attitudes towards learning.

\section{Conclusions}

Based on the findings of this study, the following conclusions were drawn:

1) The students had an insufficient knowledge when it comes to basic Mathematics skills that led them come across difficulties in solving math problems.

2) Teaching Mathematics needed an appropriate teaching strategy that depends on the level of performance of the students that will boost their confidence as wells as upgrade their mathematical skills.

3) The students' positive perception on Mathematics is a very important factor in order for them to become more attentive in class discussion.

4) Cooperative learning activities such as Group activities, peer tutoring/mentoring, group games and problem solving activities help the learners understand the concept and gain a long term mastery skills in Mathematics.

5) The cooperative learning method develops the Mathematics skills and abilities of the students and improves their learning habits more than the traditional method.

6) Through cooperative learning method, the students felt the positive attitudes toward mathematics.

7) Future studies on cooperative learning may focus on some other levels of mathematics education. The data and results gathered in this study may serve as guide to future researchers intended to determine the effects of cooperative learning to non mathematics students or in the tertiary level of education where students are inclined to do their academic works alone and with their electronic gadgets rather than in the companion of their classmates.

8) The results of the study may serve as guide to learn other approaches in teaching the subject such the use of computers, social learning, and simulation and many others. 


\section{Recommendation}

Based on the foregoing findings of the study, the following recommendations were offered:

1) For Mathematics teachers, it is recommended that cooperative learning method should be applied during instruction on selected topics suited to those students who belong to heterogeneous groups.

2) School Administrators should give attention on remediation programs and planning on instructional intervention to prevent the difficulties of students on basic Mathematics skills through cooperative learning method.

3) Curriculum guide provided to all teachers may be improved focusing on teaching and learning process where cooperative learning method is integrated in difficult topics.

4) Trainings on procedure and development of materials for cooperative learning method may be conducted to open the awareness of teachers and students on this kind of teaching and learning strategy.

5) Similar studies may be conducted by future researcher for other subjects or to other respondents having different characteristics.

\section{References}

[1] Johnson, D.W., Johnson, R.T. and Smith, K.A. (2014) Cooperative Learning: Improving University Instruction by Basing Practice on Validated Theory. Journal on Excellence in University Teaching, 25, 1-26.

[2] Conway, A., Fatisson, P.-E., Eickemeyer, P., Cheng, J. and Peters, D. (2012) Urban Micro-Consolidation and Last Mile Goods Delivery by Freight-Tricycle in Manhattan: Opportunities and Challenges. Transportation Research Board 91 st Annual Meeting, Washington DC, 22-26 January 2012.

[3] Hänze, M. and Berger, R. (2007) Cooperative Learning, Motivational Effects, and Student Characteristics: An Experimental Study Comparing Cooperative Learning and Direct Instruction in 12th Grade Physics Classes. Learning and Instruction, 17, 29-41. https://doi.org/10.1016/j.learninstruc.2006.11.004

[4] Bruffee, K.A. (1995) Sharing Our Toys: Cooperative Learning versus Collaborative Learning. Change: The Magazine of Higher Learning, 27, 12-18.

https://doi.org/10.1080/00091383.1995.9937722

[5] Hooker, D. (2011) Small Peer-Led Collaborative Learning Groups in Developmental Math Classes at a Tribal Community College. Multicultural Perspectives, 13, 220-226. https://doi.org/10.1080/15210960.2011.616841

[6] Nichols, J.D. and Miller, R.B. (1994) Cooperative Learning and Student Motivation. Contemporary Educational Psychology, 19, 167-178. https://doi.org/10.1006/ceps.1994.1015

[7] Hertz-Lazarowitz, R., Kagan, S., Sharan, S., Slavin, R. and Webb, C. (2013) Learning to Cooperate, Cooperating to Learn. Springer Science \& Business Media, Berlin.

[8] Fuks, H., Gerosa, M. A., \& de Lucena, C. J. P. (2002). The Development and Application of Distance Learning Courses on the Internet. Open Learning, 17, 23-38. https://doi.org/10.1080/02680510120110157

[9] Kroll, D.L., Masingila, J.O. and Mau, S.T. (1992) Cooperative Problem Solving: But What about Grading? The Arithmetic Teacher, 39, 17. 
[10] Masingila, J.O. (1993) Learning from Mathematics Practice in Out-of-School Situations. Learning of Mathematics, 13, 18-22.

[11] Doolittle, P.E. (1997) Vygotsky's Zone of Proximal Development as a Theoretical Foundation for Cooperative Learning. Journal on Excellence in College Teaching, 8 , 83-103.

[12] Zakaria, E., Chin, L.C. and Daud, M.Y. (2010) The Effects of Cooperative Learning on Students' Mathematics Achievement and Attitude towards Mathematics. Journal of Social Sciences, 6, 272-275. https://doi.org/10.3844/jssp.2010.272.275 